\section{Shoot Regeneration in Vitro from Diverse Genotypes of Sweetpotato and Multiple Shoot Production per Explant}

\author{
Ramana M. Gosukonda ${ }^{1}$, C.S. Prakash ${ }^{2}$, and Ananta Porobo Dessai ${ }^{3}$ \\ Plant Molecular and Cellular Genetics Laboratory, School of Agriculture and \\ Home Economics, Tuskegee University, Tuskegee, AL 36088-1641
}

Additional index words. Ipomoea batatas, biotechnology, organogenesis, tissue culture, thidiazuron, $N^{6}$-(2-isopentenyl) adenine, explant variables

\begin{abstract}
Studies were conducted to improve adventitious shoot regeneration in sweetpotato [Ipomoea batatas (L.) Lam.], specifically to extend the protocol to many genotypes and to elicit production of multiple shoots per explant. The use of a two-stage procedure where excised petioles were incubated on Murashige and Skoog (MS) (1962) medium with 2,4-D $\left(0.2 \mathrm{mg}^{\left.-l i t e r^{-1}\right)}\right.$ for 3 days and transferred to a second medium containing MS salts with thidiazuron and $2 \mathrm{iP}\left(0.05 \mathrm{mg}^{-}\right.$liter $^{-1}$ each $)$ resulted in shoot regeneration from eight of 13 genotypes tested, including elite sweetpotato cultivars such as 'Jewel' and 'Rojoblanco'. PI 318846-3 was the most regenerable genotype, with up to $77 \%$ of explants producing one to three shoots per explant. The orientation of the petiole on the nutrient medium was critical; those placed vertically inverted developed multiple shoots. Wounding explants through epidermal peeling with normal horizontal orientation of the explants during incubation also resulted in multiple shoot production (about three shoots per explant). Interference with auxin transport due to explant inversion or wounding may have stimulated increased shoot induction. Chemical names used: 2,4 dichlorophenoxyacetic acid (2,4-D); $N$-phenyl- $N^{\prime}-1,2,3$-thiadiazol-5-ylurea (thidiazuron); $N^{6}$-(2-isopentenyl) adenine (2iP).
\end{abstract}

There are several reports of in vitro regeneration of sweetpotato plants either adventitiously or via somatic embryogenesis (Kuo, 1991). However, most of these approaches result in a low frequency of shoot regeneration and have been of limited use in the development of transgenic sweetpotato plants with normal phenotype (Al-Juboory and Skirvin, 1991; Otani et al., 1993; Prakash and Varadarajan, 1992). When a two-stage system of culture was employed with petiole explants pulsed with 2,4-D $\left(0.2 \mathrm{mg} \cdot \mathrm{liter}^{-1}\right)$ for 2 to 3 days and then cultured on a medium containing thidiazuron (TDZ; $0.2 \mathrm{mg} \cdot \mathrm{liter}^{-1}$ ), most petiole explants of sweetpotato developed adventitious shoots (>80\%) (Gosukonda etal., 1995). However, regeneration was limited to the production of one shoot per explant and only in a few sweetpotato genotypes. For the regeneration protocol to be useful in the devel-

Received for publication 9 Dec. 1994. Accepted for publication 26 May 1995. Contribution no. 246 of the George Washington Carver Agricultural Experiment Station. We thank Korsi Dumenyo and Matand Kanyand for their technical assistance. Research supported by grants from U.S. Dept. of Agriculture (ALX-9201871), U.S. Agency for International Development (DAN 5053G0000580 C), and National Aeronautics and Space Administration (NAGW-2940). The cost of publishing this paper was defrayed in part by the payment of page charges. Under postal regulations, this paper therefore must be hereby marked advertisement solely to indicate this fact.

${ }^{1}$ Graduate Student.

${ }^{2}$ Associate Professor; to whom reprint requests should be addressed.

${ }^{3}$ Postdoctoral Research Associate. opment of transgenic plants or the production of useful somaclonal variants, it is desirable to develop a tissue culture system that results in several shoots per explant and protocol applicable to various genotypes.

Agrobacterium tumefaciens has been used successfully as a vector for the genetic transformation of dicotyledonous plants. Explants are usually wounded before Agrobacterium cocultivation, as the release of phenolic compounds from injured plant cells that activate vir genes are critical to T-DNA transfer (Horsch et al., 1986). To enhance transformation, the explant area exposed to wounding often needs to be increased. However, it is critical to ensure that such explant wounding does not adversely affect regeneration potential. Explant orientation during incubation also affects shoot induction and proliferation in other crops, such as soybean [Glycine max (L.) Merr.] (Kim et al., 1990) and apple (Malus domestica Borkh.) (Zimmerman and Fordham, 1989).

The objective of this research was to develop an improved plant regeneration system for sweetpotato, specifically to 1) extend the regeneration protocol to many genotypes; 2) produce multiple shoots per explant; and 3) investigate the effect of surface-injury, combined with the orientation of explants, on shoot regeneration.

\section{Materials and Methods}

Plant material. The sweetpotato genotypes used in this study were obtained as in vitro shoot tips from the U.S. Dept. of Agriculture/ Agricultural Research Service Regional Plant
Introduction Station, Griffin, Ga. (Jarret, 1989). As sweetpotato is vegetatively propagated, each genotype thus represents a clone. Plants were maintained as shoot cultures in vitro using a multiplication medium consisting of Murashige and Skoog (MS) (1962) salts with (in mg.liter ${ }^{-1}$ ) 100 myoinositol, 0.4 thiamine hydrochloric acid, 100 L-arginine, 200 ascorbic acid, 2 pantothenic acid, 20 putrescine, and 20 gibberellic acid (Dodds et al., 1991) with 3.5 g Phytagel/liter (Sigma Chemical Co., St. Louis) used as a gelling agent. The $\mathrm{pH}$ of the media throughout this study was adjusted to 5.8 (before Phytagel addition). The medium was poured $\left(40 \mathrm{ml}\right.$ ) into $\mathrm{GA}_{7}$ vessels (Magenta Co., Chicago) and autoclaved at $121 \mathrm{C}$ at 1.1 $\mathrm{kg} \cdot \mathrm{cm}^{-2}$ for $20 \mathrm{~min}$. Stock plants were subcultured every 4 to 6 weeks using nodal sections (at least three nodes per explant) that were placed horizontally on the medium. The vessels were wrapped with parafilm. All plants were incubated in growth chambers at $25 \pm 3 \mathrm{C}$ with a 16-h light/8-h dark photoperiod. Light $\left(50 \mu \mathrm{mol} \cdot \mathrm{m}^{-2} \cdot \mathrm{s}^{-1}\right)$ was produced by cool-white fluorescent tubes combined with Grolux tubes (2:1).

Explants and culture. Petiole pieces (5 to $10 \mathrm{~mm}$ ) isolated from apical leaves were used as explants. The basal end of the petiole was removed ( 1 to $2 \mathrm{~mm}$ ) to eliminate any potential axillary meristem. A two-stage protocol was followed throughout: the stage I culture consisted of basal medium supplemented with 2,4-D at $0.2 \mathrm{mg} \cdot \mathrm{liter}^{-1}$. The basal medium was composed of inorganic MS salts, myoinositol (100 mg.liter $\left.{ }^{-1}\right)$, thiamine- $\mathrm{HCl}\left(0.4 \mathrm{mg} \cdot \mathrm{liter}^{-1}\right)$, sucrose $(3 \% \mathrm{w} / \mathrm{v})$, and Phytagel $(0.35 \% \mathrm{w} / \mathrm{v})$. In stage II, the basal medium was supplemented with 2iP, TDZ, or both, depending on the study. Control treatments included TDZ at $0.2 \mathrm{mg} \cdot \mathrm{liter}^{-1}$, as this treatment was found to result in the highest shoot regeneration response in genotype PI 318846-3 in our previous study (Gosukonda et al., 1995). However, further preliminary studies showed that when $2 \mathrm{iP}$ was added to the stage II medium, it was necessary to reduce the concentration of TDZ from 0.2 to $0.05 \mathrm{mg}$ liter ${ }^{-1}$. When $2 \mathrm{iP}$ was used without TDZ, shoot regeneration failed. Four 2iP levels (0.02, 0.05, 0.08 and 0.2 mg.liter $\left.^{-1}\right)$ were tested in the stage II medium containing TDZ at $0.05 \mathrm{mg} \cdot \mathrm{liter}^{-1}$. All growth regulators were filter-sterilized and added to the autoclaved media before dispensing $(25 \mathrm{ml})$ into $100 \times 15$-mm petri dishes. Most chemicals used in this study were obtained from Sigma Chemical Co., while TDZ was purchased from Crescent Chemical (Hauppauge, N.Y.).

Petiole explants were placed horizontally on the nutrient medium in stage I, and the orientation of the explant on the stage II media varied with the type of experiment (Fig. 1). In the study on testing various levels of $2 \mathrm{iP}$, explants of various genotypes were placed vertically with their bases embedded inside the nutrient medium. To assess the effect of surface injury of explants on shoot regeneration, petiole explants of PI 318846-3 were scraped using a fine scalpel to remove the epidermal (and possibly subepidermal) tissues across the petiole (Fig. 2A). The effect of 

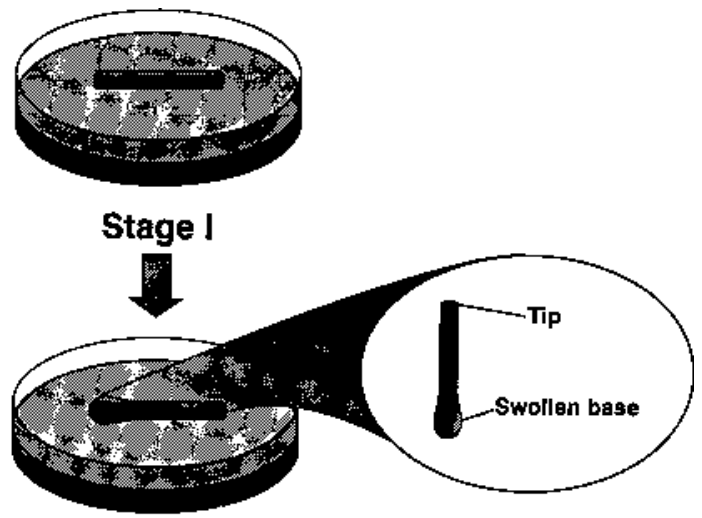

2-4 Days Later

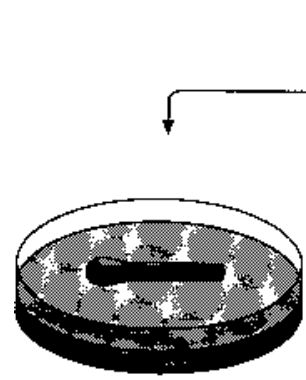

Horizontal
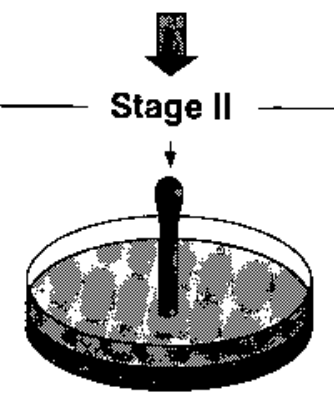

Vertical- inverted

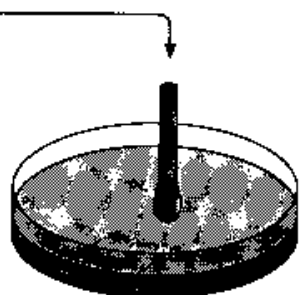

Vertical- upright

Fig. 1. Diagrammatic representation of petiole orientations tested during stage II (Murashige and Skoog + thidiazuron, $0.2 \mathrm{mg} \cdot$ liter $^{-1}$ ).

explant orientation on shoot regeneration was tested on the surface-injured and noninjured petioles of PI 318846-3 by placing petioles in a horizontal, vertically inverted (where the distal end of the petiole was inserted inside the nutrient medium), or vertically upright on the stage II medium (Fig. 1).

Explants were incubated on the stage I medium for 3 days and then transferred to the stage II medium. Incubation of petioles on stage II media lasted 4 to 6 weeks, depending on the study. A completely randomized design was employed in all the studies. At least six explants were included in each petri dish, which served as a replication, and there was a minimum of three replications per treatment. All experiments were conducted at least twice. The regeneration frequency was computed as percentage of explants showing at least one adventitious shoot. The data collected from each experiment were subjected to statistical analysis as outlined by Steel and Torrie (1980) using the statistical package MMSTAT (Maloney, 1983) on the DEC VAX 11/780 minicomputer.

\section{Results}

Effect of $2 i P$ levels with TDZ on petiole organogenesis. Sweetpotato petioles were pulsed with 2,4-D for 3 days. At the end of this period, petioles typically exhibited swelling at the basal end (Fig. 2A). Subsequently, they were transferred to a medium containing TDZ supplemented with various levels of $2 \mathrm{iP}(0.02$ to $0.2 \mathrm{mg} \cdot \mathrm{liter}^{-1}$ ). When cultured on a medium containing TDZ at $0.2 \mathrm{mg} \cdot \mathrm{liter}^{-1}$ without $2 \mathrm{iP}$, adventitious shoot production was confined to PI 318846-3 (Table 1). When $2 \mathrm{iP}$ was included at various levels, along with a reduced level of TDZ (0.05 mg.liter $\left.{ }^{-1}\right)$, adventitious shoots were produced in additional genotypes of sweetpotato. The inclusion of $2 \mathrm{iP}$ at 0.02 or $0.2 \mathrm{mg} \cdot \mathrm{liter}^{-1}$ (in addition to TDZ at 0.05 $\left.\mathrm{mg} \cdot \mathrm{liter}^{-1}\right)$ resulted in the regeneration of shoots in three sweetpotato genotypes ('Hi-Dry', PI 531143, and PI 318846-3); when 2iP was included at $0.08 \mathrm{mg} \cdot \mathrm{liter}^{-1}$, two additional genotypes produced shoots (PI 508507 and PI 318846). Best regeneration response was obtained when explants were cultured in the stage II medium containing $2 \mathrm{iP}$ at $0.05 \mathrm{mg}^{-1 \text { liter }^{-1}}$ with TDZ (0.05 mg.liter $\left.{ }^{-1}\right)$, where eight genotypes formed adventitious shoots (Table 1). This group Included 'Jewel', 'Rojo Blanco', and PI 508513, none of which regenerated shoots at any other combination of cytokinins tested. Across treatments, PI 318846-3 was the most responsive genotype, followed by PI 531143 (Table 1). Genotypes 'White Star', PI 318856, PI 318852 , PI 318849 , and PI 318848 also were included in the test, but none produced shoots under any treatment.

When $2 \mathrm{iP}$ was included in the stage II

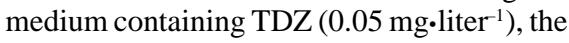
quality of sweetpotato plants obtained also was improved. Shoots that developed when TDZ was used without $2 \mathrm{iP}$ were small with short internodes and occasionally had malformed leaves. The plantlets developed fewer roots when continually cultured on TDZ $(0.2$ $\mathrm{mg} \cdot$ liter $\left.^{-1}\right)$. In contrast, those shoots induced using 2iP with a lower level of TDZ (0.05 $\mathrm{mg} \cdot$ liter $^{-1}$ ) were healthy and vigorous. All the sweetpotato shoots obtained using either TDZ at $0.2 \mathrm{mg} \cdot \mathrm{liter}^{-1}$ or TDZ at $0.05 \mathrm{mg} \cdot \mathrm{liter}^{-1}$ plus $2 \mathrm{iP}$ at $0.05 \mathrm{mg} \cdot \mathrm{liter}^{-1}$ rooted when such shoots were cultured on the multiplication medium.

Effect of surface injury and explant orientation on organogenesis in PI 318846-3. Less than $40 \%$ of petioles surface-injured by epidermal peeling, when cultured in the normal vertical-upright positioning during the second stage (Fig. 1), produced adventitious shoots; in contrast, more than three-fourths of nonwounded petioles with similar orientation regenerated shoots (Table 2). However, when wounded petiole explants were placed either horizontally or in a vertically inverted manner on the nutrient medium (Fig. 1), shoot regeneration frequencies were high $(>70 \%)$ compared to the nonwounded control petioles (Table 2). The most significant impact of tissue injury to the explants was the number of shoots produced by regenerative explants when located horizontally on the nutrient medium. The wounded explants produced an average of three shoots per explant, in contrast to one per nonwounded explants (Table 2). Surface injury also resulted in the production of multiple shoots from petioles placed vertically upright on the nutrient medium. Such multiple shoot production was also observed in petioles placed vertically inverted, irrespective of the tissue injury (Fig. 2 B and C).

In the analysis of variance, the wounding was a significant determinant for the variation in number of shoots produced $(P<0.031)$, while there was a significant interaction between explant wounding and the explant orientation for percent shoot regeneration $(P<$ 0.009 ) (data not shown). The combination of surface injury and the manipulation of explant orientation markedly increased the average number of shoots produced per regenerable explant. In repeat studies, we have observed up to six shoots per explant. Callus was observed throughout the surface of injured petioles, while in nonwounded petioles such callus was restricted to the basal portion (Fig. 2A). Surface injury also altered the sites of regeneration, as shoots from wounded explants arose from sites farther away from the basal end, while in nonwounded petioles, shoots developed only at the basal cut end. There was a delayed initiation of shoots from surface-wounded explants when compared to those from control nonwounded explants. Shoot primordia appeared initially as small, multiple, pigmented spots on calli. These spots represented foci of intense meristematic zones and developed into multiple shoots (Fig. 2 B and C).

\section{Discussion}

We report here an improved protocol for the in vitro shoot regeneration from sweetpotato petioles, an organ known to be relatively more competent than leaves for genetic transformation using Agrobacterium tumefaciens (Prakash and Varadarajan, 1992) and earlier reported to be recalcitrant to shoot regeneration (Dodds et al., 1992). Our earlier studies using TDZ have shown that shoot organogenesis can be 

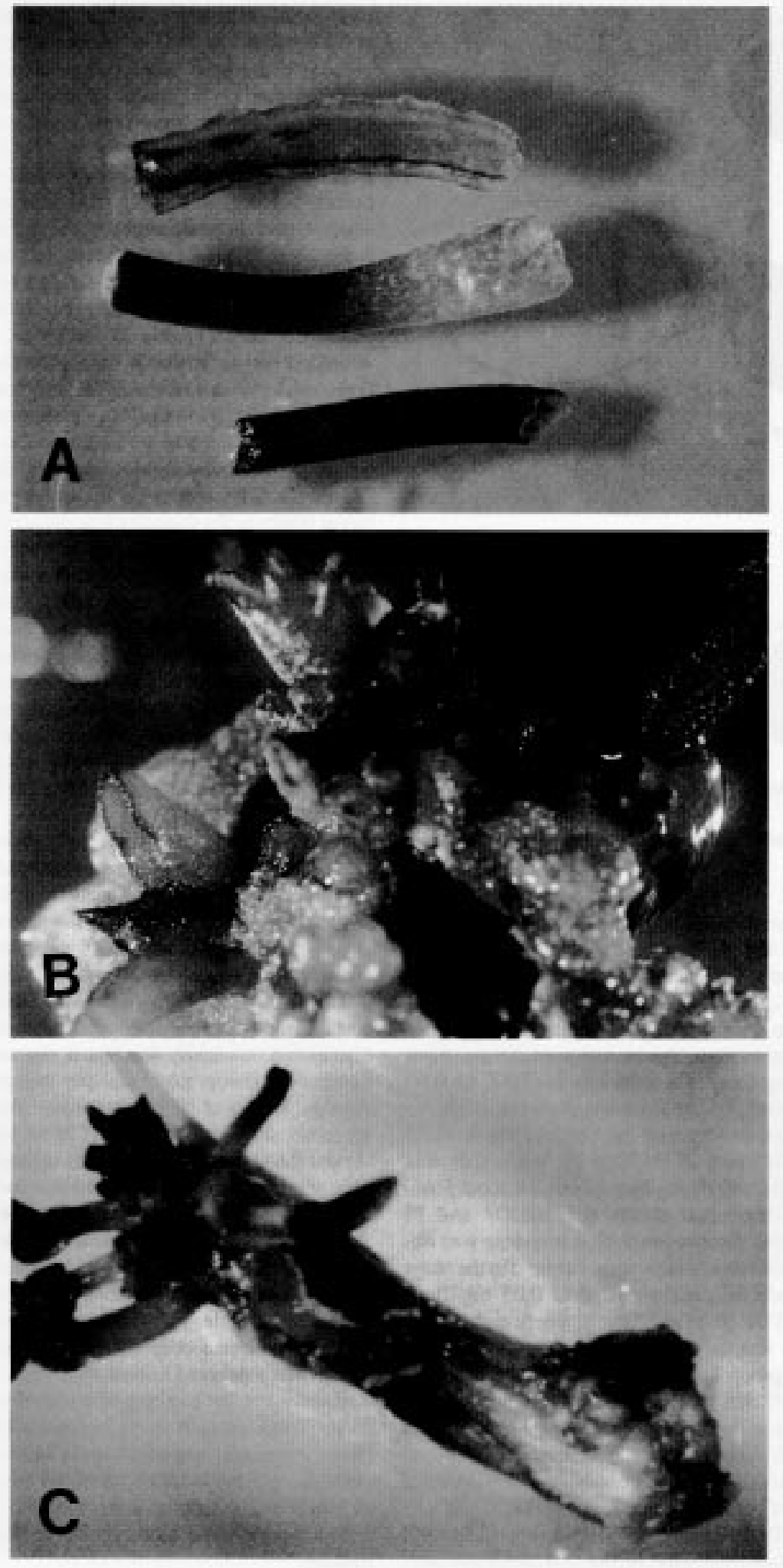

Fig. 2. Adventitious regeneration of plants in sweetpotato genotype PI 318846-3 using petiole explants. (A) Sweetpotato petiole explants (bottom) before culture, (middle) after culture on stage I medium

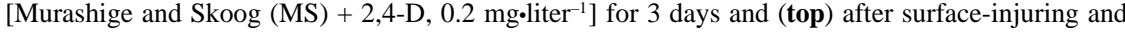

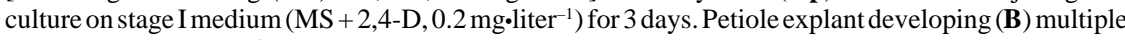
shoot primordia and $(\mathbf{C})$ shoots at its basal end when cultured in an inverted-vertical manner on MS medium supplemented with thidiazuron, $0.2 \mathrm{mg} \cdot \mathrm{liter}^{-1}$ (stage II).

achieved from petiole explants of the genotype PI 318846-3 (Gosukonda et. al., 1995). The present study shows that supplementing $2 \mathrm{iP}$ with a reduced level TDZ (0.05 $\left.\mathrm{mg} \cdot \mathrm{liter}^{-1}\right)$, further extends the spectrum of regenerable sweetpotato genotypes using petiole explants. Elite sweetpotato cultivars such as 'Rojo Blanco' and 'Jewel', whose petioles could not be regenerated using any previous treatments, produced shoots when cultured on a medium with TDZ and 2iP (Table 1). Overall, PI 318846-3 was the most responsive genotype across the treatments and consistently produced the highest frequency of shoot regeneration. Sweetpotato plantlets obtained from TDZ and 2iP medium were superior in quality to those obtained from TDZ medium alone. Briggs et al. (1988) have also observed that TDZ-induced azalea (Rhododendron spp.) shoots were of low quality compared to those induced by TDZ and $2 \mathrm{iP}$.

The development of multiple shoots on sweetpotato explants due to alteration of explant orientation and peeling of epidermis is difficult to explain. There are reports of increased axillary shoot production by altering explant orientation during culture (McClelland and Smith, 1990; Zimmerman and Fordham, 1989). The mechanisms involved in the induction of polarity and its fixation are obscure (Nick and Faruya, 1992). There are conflicting opinions on the nature of polarity in plants, i.e., it is either induced de novo or inherited in a stable manner (Nick and Faruya, 1992). The shoot-root polarity is defined by the basipetal movement of auxin, and disruption of this polar auxin transport either by explant inversion or wounding may lead to auxin depletion, as suggested by Nick and Faruya (1992), with consequent changes in the ability of the tissue to produce adventitious shoots. Tamas et al. (1989) also observed that the polarity of auxin transport was a critical factor in axillary bud growth of Phaseolus vulgaris. L. Further studies are needed to investigate in detail the effect of tissue polarity on shoot organogenesis in sweetpotato.

The combination of surface injury along with explant orientation not only increased the average number of shoots per regenerable explant but also altered the site of regeneration on the explant. On surface-injured explants, shoots were produced at the center of the petiole, away from the cut ends, possibly due to the improved access of plant growth regulators or translocatable wound response factors. Jong et al. (1993) found that wounding of chrysanthemum [Dendranthema $\times$ grandiflorum (Ramat.) Kitamura] leaf explants increased the number of shoots per explant, although it did not change the sites of regeneration. The inverted sweetpotato petioles produced twice as many shoots as the control (vertically upright). Furthermore, surface-injured petioles placed horizontally produced three times as many shoots per explant as petioles placed vertically upright in stage II medium.

Having petioles oriented inverted so that shoots develop at the basal end is of practical advantage in gene transfer studies. One can specifically target the exposed basal end of the petiole to Agrobacterium application or particle bombardment. This procedure also would minimize the overgrowth of Agrobacterium after cocultivation, since the site of bacterial application will not be in contact with the nutrient medium.

In conclusion, we report an efficient and rapid method to regenerate adventitious sweetpotato plants in vitro from a wide range 
Table 1. Effect of $2 \mathrm{iP}$ levels in combination with thidiazuron (TDZ) $\left(0.05 \mathrm{mg} \cdot \mathrm{liter}^{-1}\right)$ during stage II culture on shoot regeneration frequency of petiole explants in different sweetpotato genotypes.

\begin{tabular}{|c|c|c|c|c|c|}
\hline \multirow[b]{3}{*}{ Genotype } & \multirow{3}{*}{ 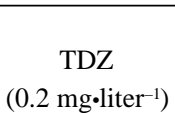 } & \multicolumn{4}{|c|}{ Explants forming shoots $(\%)^{\mathrm{z}}$} \\
\hline & & \multicolumn{4}{|c|}{ 2iP levels $\left(\mathrm{mg} \cdot \mathrm{liter}^{-1}\right)$ tested with TDZ $\left(0.05 \mathrm{mg} \cdot\right.$ liter $\left.^{-1}\right)$} \\
\hline & & 0.02 & 0.05 & 0.08 & 0.2 \\
\hline Hi-Dry & 0 & $23.9 \pm 4.8$ & $11.0 \pm 1.9$ & $11.4 \pm 2.2$ & $16.1 \pm 6.4$ \\
\hline PI 531143 & 0 & $23.8 \pm 4.8$ & $50.0 \pm 9.6$ & $44.4 \pm 6.9$ & $27.9 \pm 8.8$ \\
\hline P1 318846-3 & $85.0 \pm 7.6$ & $62.7 \pm 6.5$ & $66.7 \pm 9.6$ & $61.1 \pm 5.5$ & $61.1 \pm 14.7$ \\
\hline PI 508507 & 0 & 0 & $17.5 \pm 6.2$ & $12.9 \pm 2.7$ & 0 \\
\hline Pl 318846 & 0 & 0 & $37.3 \pm 9.7$ & $12.9 \pm 2.7$ & 0 \\
\hline Jewel & 0 & 0 & $9.4 \pm 1.7$ & 0 & 0 \\
\hline Rojo Blanco & 0 & 0 & $8.5 \pm 1.3$ & 0 & 0 \\
\hline P1 508513 & 0 & 0 & $3.3 \pm 2.5$ & 0 & 0 \\
\hline
\end{tabular}

${ }^{2}$ Mean with standard errors.

Table 2. Effect of surface injury and explant orientation on percent shoot regeneration frequency of petiole explants of sweetpotato PI 318846-3 cultured on Murashige and Skoog (MS) medium with 2,4-D (0.2 $\left.\mathrm{mg} \cdot \mathrm{liter}^{-1}\right)$ and transferred to medium with thidiazuron (TDZ) $\left(0.2 \mathrm{mg}^{\circ} \mathrm{liter}^{-1}\right)$.

\begin{tabular}{|c|c|c|c|c|c|c|}
\hline \multirow[b]{3}{*}{$\begin{array}{l}\text { Surface } \\
\text { wounding }\end{array}$} & \multicolumn{6}{|c|}{ Explant orientation } \\
\hline & \multicolumn{2}{|c|}{ Horizontal $^{2}$} & \multicolumn{2}{|c|}{ Vertically inverted } & \multicolumn{2}{|c|}{ Vertically upright } \\
\hline & $\begin{array}{c}\text { Regeneration } \\
(\%)\end{array}$ & $\begin{array}{l}\text { Avg no. } \\
\text { shoots }^{\mathrm{x}}\end{array}$ & $\begin{array}{c}\text { Regeneration } \\
(\%)\end{array}$ & $\begin{array}{l}\text { Avg no. } \\
\text { shoots }\end{array}$ & $\begin{array}{c}\text { Regeneration } \\
(\%)\end{array}$ & $\begin{array}{l}\text { Avg no. } \\
\text { shoots }\end{array}$ \\
\hline- & $44.4 \pm 11.1$ & 1.0 & $58.8 \pm 4.8$ & 1.9 & $77.7 \pm 5.5$ & 1.0 \\
\hline+ & $73.6 \pm 6.0$ & 3.0 & $74.2 \pm 5.5$ & 1.8 & $37.3 \pm 6.9$ & 2.2 \\
\hline
\end{tabular}

${ }^{2}$ Explant orientations (horizontal, vertically inverted, and vertically upright ) were applied in stage II (MS + TDZ). Surface injury inflicted before culture.

yercentage of shoot regeneration; mean and standard error.

${ }^{x}$ Shoots produced per regenerative explant.

of genotypes. The method involves a two-step protocol using 2,4-D $\left(0.2 \mathrm{mg} \cdot \mathrm{liter}^{-1}\right)$ in stage I and a combination of TDZ with $2 \mathrm{iP}(0.05$ $\mathrm{mg} \cdot \mathrm{liter}^{-1}$ each) in stage II. Vertically inverting petiole explants and surface-scraping them results in the production of multiple adventitious shoots. Plantlets produced by the abovedescribed methods appeared normal, healthy, and they have been successfully transferred to a greenhouse.

\section{Literature Cited}

Al-Juboory, K.H. and R.M. Skirvin. 1991. In vitro regeneration of Agrobacterium-transformed sweet potato (Ipomoea batatas L.). PGRSA Quarterly 19:82-89.

Briggs, B.A., S.M. McCulloch, and L.A. Edick. 1988. Micropropagation of azaleas using thidiazuron. Acta Hort. 228:205-208.
Dodds, J.H., J. Benavides, F. Buitron, F. Median, and C. Sigüeñas. 1992. Biotechnology applied to sweetpotato improvement, p. 7-19. In: W.A. Hill, C.K. Bonsi, and P.A. Loretan (eds.). Sweetpotato technology for the 21st century. Tuskegee Univ., Tuskegee, Ala.

Dodds, J.H., C. Merzdorf, V.Zambrano, C. Sigueñas, and J. Jaynes. 1991. Potential use of Agrobacterium-mediated transfer to confer insect resistance in sweet potato, p. 203-220. In: R. Jansson and K.V. Raman (eds.). Sweet potato pest management, a global perspective. Westview Press, Boulder, Colo

Gosukonda, R.M., A. Porobodessai, E.T. Blay, C.S Prakash, and C.M. Peterson. 1995. Thidiazuroninduced adventitious shoot regeneration of plants from sweetpotato (Ipomoea batatas). In Vitro Cellular Dev. Biol. Plant 31:65-71.

Horsch, R.B., H.J. Klee, S.C. Winans, E.W. Nester, S.G. Rogers, and R.T. Fraley. 1986. Analysis of Agrobacterium tumefaciens virulence mutants in leaf discs. Proc. Natl. Acad. Sci. 83:25712575.

Jarret, R.L. 1989. A repository for sweet potato germplasm. HortScience 24:886.

Jong, J.D., W.R. Maker, and M.F. Wordragen. 1993. Restoring adventitious shoot formation on chrysanthemum leaf explants following cocultivation with Agrobacterium tumefaciens. Plant Cell Tissue Organ Cult. 32:263-270.

Kim, J., C.E. Lamotte, and E. Hack. 1990. Plant regeneration in vitro from primary leaf nodes of soybean (Glycine max) seedlings. J. Plant Physiol. 136:664-669.

Kuo, C.G. 1991. Conservation and distribution of sweet potato germplasm, p. 123-147. In: J.H. Dodds (ed.). In vitro methods for conservation of plant genetic resources. Chapman and Hall, New York.

Maloney, M.A. 1983. MMSTAT. George Washington Carver Expt. Sta., Tuskegee Univ., Tuskegee, Ala.

McClelland, T. and M.A.L. Smith. 1990. Vessel type, closure, and explant orientation influence in vitro performance of five woody species. HortScience 25:797-800.

Murashige, T. and F. Skoog. 1962. A revised medium for rapid growth and bioassays with tobacco tissue cultures. Physiol. Plant. 15:473497.

Nick, P. and M. Faruya. 1992. Induction and fixation of polarity-Early steps in plant morphogenesis. Dev. Growth Differ. 34:115-125.

Otani, M., M. Mii, T. Handa, H. Kamada, and T. Shimada. 1993. Transformation of sweet potato [Ipomoea batatas (L.) Lam.] plants by Agrobacterium rhizogenes. Plant Sci. 94:151159.

Prakash, C.S. and U. Varadarajan. 1992. Genetic transformation of sweetpotato, p. 27-37. In: W.A. Hill, C.K. Bonsi, and P.A. Loretan (eds.). Sweetpotato technology for the 21st century. Tuskegee Univ., Tuskegee, Ala.

Steel, R.G.D. and J. H. Torrie. 1980. Principles and procedures of statistics, a biometrical approach. McGraw-Hill, New York.

Tamas, I.A., J.L. Schlossberg-Jacobs, R. Lim, L.B. Friedman, and C.C. Barone. 1989. Effect of plant growth substances on the growth of axillary buds in cultured stem segments of Phaseolus vulgaris L. Plant Growth Regulat. 8:165-183.

Zimmerman, R.H. and I. Fordham. 1989. Explant orientation affects axillary shoot proliferation of apple cultivars in vitro. HortScience 24:351352. 